\title{
Provisional Crown Failures in Dental School Predoctoral Clinics
}

\begin{abstract}
Jeffrey D. Hyde, D.D.S.; James A. Bader, D.D.S., M.P.H.; Daniel A. Shugars, D.D.S., Ph.D. Abstract: Following a preliminary study indicating that at least 10 percent of single-unit crown temporary restorations failed in patients who received treatment by predoctoral students, a comprehensive examination of provisional crown failure was initiated to identify strategies to reduce the failure rate. For all provisionalized, natural tooth, single-unit crown preparations in University of North Carolina School of Dentistry predoctoral clinics for one year ( $\mathrm{N}=1008)$, we noted tooth type, type of crown, student level, faculty coverage experience, treatment clinic, temporary material and luting agent, and retreatment (failure) of the provisional restoration. For failures, we also noted the stage of crown preparation at failure and the time since initial placement of the temporary. We analyzed these data using simple cross-tabs and logistic regression on need for retreatment $(\alpha=0.05)$. The failure rate was 18.75 percent $(\mathrm{N}=189)$. The median time to failure was twelve days; the $25^{\text {th }}$ and $75^{\text {th }}$ percentiles were six and twenty-six days. Significant risk factors, in order of odds ratio estimates, were molar tooth, second- or third-year student, and inexperienced faculty. Most provisional failures occurred during the final preparation phase of treatment. Provisional restoration failure is more frequent than was initially suspected from preliminary studies. Strategies for institutional intervention to reduce provisional restoration failure include greater attention to evaluating provisional crowns placed by inexperienced students (sophomores and juniors) and placing more emphasis on the retentiveness of provisional restorations reused following the final impression. Review of provisional evaluation procedures is also indicated for faculty who do not routinely supervise these procedures.
\end{abstract}

Dr. Hyde is a Graduate Student, Department of Orthodontics, University of Washington School of Dentistry; Dr. Bader is Research Professor, Department of Operative Dentistry, University of North Carolina School of Dentistry; and Dr. Shugars is Professor, Department of Operative Dentistry, University of North Carolina School of Dentistry. Direct correspondence and requests for reprints to Dr. Jeffrey D. Hyde, University of Washington School of Dentistry, Department of Orthodontics, D-569 Health Sciences, Box 357466, Seattle, WA 98195; 206-543-5788 phone; 206-685-8163 fax; jeffhyde@u.washington.edu.

This research was supported through a Dental Research Fellowship from the University of North Carolina Dental Research Center, 2006.

Key words: prosthodontics, quality assurance, teaching, prostheses

Submitted for publication 5/8/07; accepted 9/5/07

$\mathrm{T}$ The importance of a provisional crown to treatment outcomes is well established. The term "provisional" is preferred over the more informal term "temporary" and denotes "serving for the time being, as a necessary step in providing for the final arrangement." "Few discussions on the typical serviceable duration of provisional crowns exist in the literature. Christensen ${ }^{2}$ points to two weeks as the usual time between tooth preparation and seating of a crown, noting that after this time the typical eugenol-based temporary cement starts to break down. It is generally expected that a provisional crown will last from the time of initial tooth preparation until replacement with the permanent prosthetic crown, with little or no need for recementation or alteration. The provisional crown protects the pulp from thermal and chemical insults after crown preparation and enamel removal have been performed. ${ }^{3}$ In addition, the provisional crown serves to maintain gingival health and contour while providing for an esthetic and/or functional interim restoration. ${ }^{4}$ Adequately fabricated provisionals should also be easily cleaned and not impinge on the tissues, a condition that can cause hypertrophy or recession of marginal gingiva. Finally, the provisional crown maintains interocclusal and intra-arch tooth relationships. ${ }^{5-7}$

Given the importance of provisional crowns, concern arose when a recent pilot study ${ }^{8}$ conducted at the University of North Carolina at Chapel Hill (UNC) School of Dentistry found that 10 percent of all single-unit provisional crowns placed in UNC predoctoral clinics during a six-month period were subsequently replaced or repaired in the Urgent Care Clinic (UCC), with nearly two-thirds of these failures occurring within two weeks of initial placement. These provisional crown data arose out of a Quality Assurance Committee initiative examining treatment patterns of patients of record at the UCC, where 37 percent of recorded visits were due to provisional restoration retreatments.

This preliminary study identified provisional crown placement as an area of concern needing further inquiry, but the study fell short of providing an accurate assessment of the incidence of provisional 
failure in school clinics or identifying reasons for these failures that would direct quality improvement efforts. Additionally, there are no other reports in the literature that could furnish data for comparison. Specific to a dental school setting, Oginni ${ }^{9}$ reported failure rates for crowns and fixed partial dentures, but not the preceding provisional restorations. Various in vitro studies have looked at materials and cements used in making provisional restorations to identify an increased risk of failure, notably the fracture resistance and toughness of provisional resin materials ${ }^{10-13}$ and the negative effect of provisional luting agents on final bond strengths of resin-based cements. ${ }^{14-16}$ The literature contains numerous reports of clinical outcomes data on the various types of prosthodontic treatments, including ceramic crown evaluations, ${ }^{17}$ success rates of root-form implant systems, ${ }^{18}$ longevity of posts in endodontically treated teeth, ${ }^{19}$ and survival rates for fixed partial dentures. ${ }^{20}$ Most current research on provisional restorations revolves around the success rates of new protocols involving the immediate provision of dental implants. ${ }^{21,22}$ However, no study has reported clinical failure rates of conventional natural tooth provisional crowns in either a private practice or educational setting.

A definitive retrospective study was thus initiated to obtain a better estimate of the incidence of provisional failures and to identify risk factors that could be addressed to reduce the rate of these failures in student clinics. The results of the study should provide information useful in reducing provisional retreatment in the UCC, thereby improving both patients' treatment experiences and the UCC's availability for other types of care. Moreover, these results could be compared to those at other dental schools to begin to develop benchmarks for institutional QA activities as called for in the ADA accreditation standards. ${ }^{23}$

\section{Methods}

We conducted a retrospective study identifying all full-coverage, single-unit crown preparations (ADA codes 2750-2790) placed by predoctoral students in the School of Dentistry during a one-year period using clinical data entered into the school's Electronic Patient Record (EPR) system. The EPR is a comprehensive in-house paperless charting system that digitizes all patient histories, clinical charting/ exams, treatment plans/activity, and progress notes. Besides simplifying day-to-day record keeping, the
EPR system facilitates systematic data analysis of patient care by allowing searches by service area, ADA code, chart numbers, faculty/student provider, tooth number, etc. All data with identifiers remained with the investigators, and only summary data were reported. Numerical identifiers were used for patients, providers, and faculty to maintain confidentiality. The UNC Biomedical Institutional Review Board approved the study protocol.

Selection criteria were all natural tooth, singleunit crown preparations in progress in predoctoral clinics from August 1, 2004 through July 31, 2005. Crowns in progress at the end of the study period but not delivered were included because these teeth carried provisional crowns and were considered at risk for failure. Similarly, teeth where the crown was in progress at the beginning of the study period were included from the study date until the crown was delivered. A total of 1008 teeth with a crown procedure in progress during some portion of the one-year period were identified. These single-unit crown procedures established a risk population for provisional failure. Crowns initiated by a student but completed by faculty or residents in dental faculty practice or graduate clinics were excluded from the study. Fewer than five crowns were excluded.

The electronic treatment notes for each of the identified procedures were audited to record available information describing characteristics of the procedure hypothesized as relevant to the success of the provisional crown. These characteristics included provisional luting agent, provisional material, tooth type, treatment clinic, experience of supervising faculty (supervising ten or fewer crowns during the year versus more than ten), experience of the dental student (sophomores and juniors versus seniors), and final crown design. Each characteristic was dichotomized as shown in Table 1 and subsequently treated as a "risk indicator." In addition, if a provisional failure was identified, the stage of preparation at failure was noted.

The UNC School of Dentistry preclinical prosthodontic curriculum emphasizes an indirect method of provisional crown fabrication, using either a preoperative shim made from a VPS intraoral impression in a quadrant tray or a clear plastic stent made off of a preliminary cast. Integrity ${ }^{\circledR}$ by Dentsply Caulk is the provisional material of choice, although stainless steel, aluminum composite prefabricated shell crowns, and C\&B Resin are all available for crown fabrication. The luting agent most often used is eugenol-based Tempbond $\AA$, with oc- 


\begin{tabular}{|c|c|}
\hline Risk Indicator & Definition of Two Categories \\
\hline Luting cement & Tempbond $®$ vs. all others \\
\hline Provisional material & Integrity® vs. all others \\
\hline Tooth type & Molar vs. premolar and anterior \\
\hline Treatment clinic & Comprehensive Care vs. Fixed Prosthodontic \\
\hline Faculty experience & $>10$ crowns supervised during the year vs. $<11$ \\
\hline Student experience & Second- or third-year vs. fourth-year \\
\hline Crown design & All gold vs. porcelain or PFM \\
\hline Preparation stage* & Initial vs. final preparation or impression \\
\hline \multicolumn{2}{|c|}{ *Only for failed provisional crowns } \\
\hline
\end{tabular}

number of days between the previous treatment visit and the retreatment visit defined the days to failure. For purposes of characterizing the stage of crown preparation, the final prep/ impression stage was defined as any treatment visit when tooth preparation was deemed completed and/or a final impression was attempted. The initial prep phase was defined as any treatment visit when initial tooth preparation, both axial and occlusal reduction, was initiated but final margination was not completed.

Univariate analyses of failure rate by crown type, tooth type, clinic type, and student and faculty experience were conducted using Fisher's Exact Test. Significance was set at alpha $<0.05$. Using a pre-study assumption of 160 failures (10 percent) of 1600 provisional crowns, the study power to detect a difference of 20 percent in prevalence of any specific risk indicator between failures and non-failures was greater than 0.92 at any prevalence rate for a risk factor in the non-failure group. The factors that contributed significantly $(p<0.05)$ to provisional crown failure were further analyzed through multivariable logistic regression to identify their individual contributions to the overall risk for provisional failure. For all these analyses, failure could occur more than once for any given crown procedure, but because multiple failures were virtually nonexistent, no statistical adjustment was made for such occurrences. Also, no adjustment was made for incomplete risk observation periods resulting from procedures either being initiated or completed outside of the reporting year.

\section{Results}

During the one-year study period, 189 of 1008 provisional crowns failed, a failure proportion of 18.75 percent (Figure 1). The mean time to failure was 25.8 days, with outliers ranging from one to 390 days. As shown in Figure 2, over 50 percent of failures occurred less than two weeks from initial placement.

Table 2 shows the proportions of provisional crowns that failed for both categories of each risk factor. In general, being in the "riskier" category for any given risk indicator elevated the failure proportion from around 15 percent to around 25 percent. 


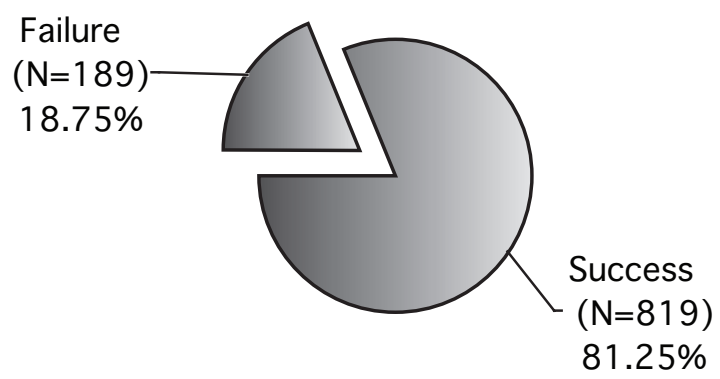

Figure 1. Annualized provisional crown failure rate

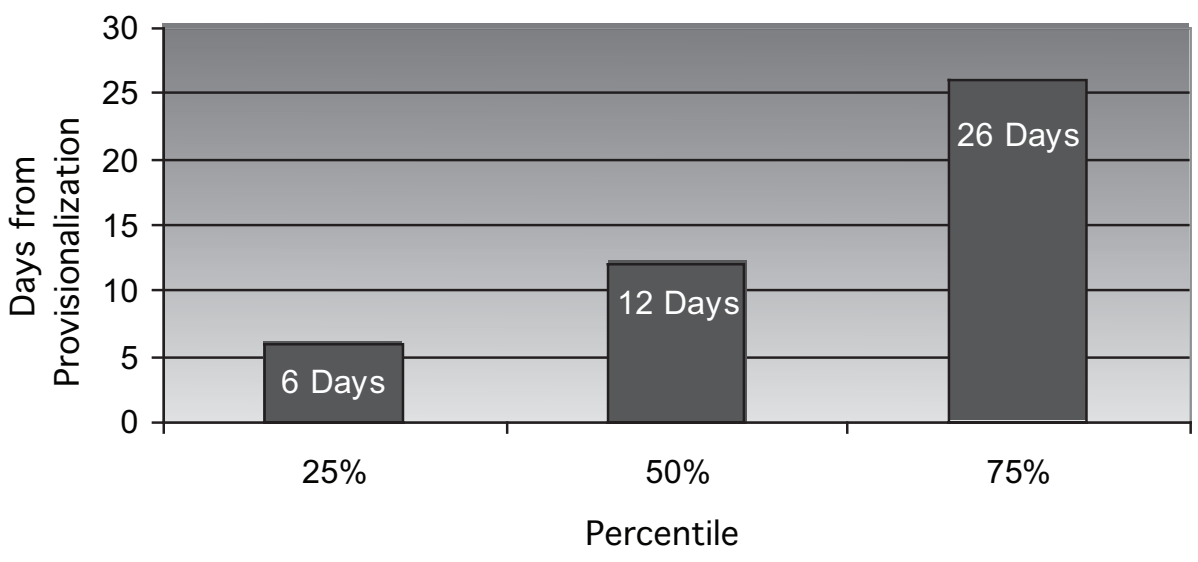

Figure 2. Median days to failure $(\mathrm{N}=189)$

All differences in failure proportions were statistically significant. For the risk indicators of luting cement and provisional material, too few procedures involved alternatives to Tempbond ${ }^{\circledR}$ and Integrity ${ }^{\circledR}$, respectively, to provide stable estimates for failure proportions and, therefore, these risk indicators were not analyzed further. As shown in Table 2, more than three-quarters of all provisional crown failures occurred when the crown preparation was in its final stage, as opposed to its initial stage.

Table 3 shows the results of a logistic regression on the five risk indicators significant in bivariate analyses. Three indicators were significant in the model. Provisional crowns for molar teeth were more than twice as likely to fail as provisional crowns for anterior and premolar teeth. Mandibular second molars showed the highest overall failure proportions.
Tooth \#18 had a failure proportion of 34 percent, and tooth \#31 had a proportion of 36 percent. Provisional crowns placed by students with less experience had double the odds of failure, and provisional restorations supervised by less experienced faculty also had a greater likelihood of failure.

\section{Discussion}

Provisional crown failure is more frequent than was initially suspected from the preliminary study, and even these results may underestimate the failure proportion because some provisionals were not observed for their full duration in the mouth. The results indicate that molar provisional crowns in both arches are at significantly higher risk of failure 
Table 2. Failure proportion by risk indicator

\begin{tabular}{llll} 
Risk Category & & Comparison Category \\
\hline Molar $(\mathrm{n}=604)$ & $24 \% * *$ & $10 \%$ & Anterior or premolar $(\mathrm{n}=404)$ \\
Comp. Care clinic $(\mathrm{n}=208)$ & $25 \% *$ & $17 \%$ & Fixed Pros. clinic $(\mathrm{n}=800)$ \\
Inexperienced faculty $(\mathrm{n}=390)$ & $23 \% *$ & $16 \%$ & Experienced faculty $(\mathrm{n}=618)$ \\
Second- or third-year student $(\mathrm{n}=497)$ & $24 \% * *$ & $14 \%$ & Fourth-year student $(\mathrm{n}=511)$ \\
Porcelain or PFM crown $(\mathrm{n}=357)$ & $25 \% * *$ & $15 \%$ & All gold crown $(\mathrm{n}=651)$ \\
Final prep ( $\mathrm{n}=150)$ & $79 \% * * *$ & $21 \%$ & Initial prep $(\mathrm{n}=39)$ \\
& \\
*Significantly different from comparison characteristic at $\mathrm{p}<0.01$ Fisher's exact test \\
**Significantly different from comparison characteristic at $\mathrm{p}<0.001$ Fisher's exact test \\
$* * *$ Includes only failed preparations, significance not tested
\end{tabular}

than anterior or premolar teeth. Although we have no evidence to support specific reasons for the increased risk of provisional failures on molar teeth, inherent difficulties with moisture control, decreased clinical crown heights, and heavier occlusal forces may contribute to the failures. Students and faculty should be aware of this increased risk and take measures to implement optimal fabrication technique and also ensure sufficient faculty oversight. Sophomore and junior students, who showed a higher risk of failure, may benefit from lower faculty to student ratios and increased supervision.

The data indicate that provisionals placed at the final prep/impression stage of treatment appear to be problematic. Circumstances would suggest that these provisionals were placed on more tapered and/or reduced teeth, due to the completion of tooth preparation, or that an existing provisional was reused following the final impression. No evidence exists that suggests a specific cause for the increased risk, but proper resistance and retention form should be built into every tooth preparation, and sufficient time should be budgeted after taking the final impression to ensure a properly fitting provisional is in place before dismissing the patient. Before cementation, older provisionals being reused after the final impression should be scrutinized for cracks or breakdown stemming from the normal forces of chewing or the

Table 3. Odds ratios for risk indicators entering the model

\begin{tabular}{lcc} 
Risk Category & $\begin{array}{c}\text { Point } \\
\text { Estimate }\end{array}$ & $\begin{array}{c}95 \% \text { Confidence } \\
\text { Interval }\end{array}$ \\
\hline Molar & 2.33 & $1.74-4.05$ \\
Faculty inexperience & 1.42 & $1.02-1.98$ \\
Second- or third-year student & 2.02 & $1.55-3.51$ \\
\hline
\end{tabular}

instrumentation used to remove the provisional from the tooth. Again, attending faculty should carefully evaluate provisional adaptation, occlusion, and contours prior to signing off on clinical progress notes. Individual failure rates for each of sixty-nine attending full- and part-time faculty members supervising crown procedures during the year ranged from a low of zero failures to the maximum of 100 percent. When the faculty were grouped by the number of crowns they had supervised during the year, those supervising ten or fewer crowns were almost 1.5 times as likely to supervise a failed provisional. One suggestion for quality assurance purposes is to provide individual feedback on failure rates in an administrative or group setting to encourage improved oversight of predoctoral treatment procedures.

Due to the near uniformity in the results for provisional material type (Integrity ${ }^{\circledR}$ bis-GMA) and luting agent (Tempbond $\AA)$, these factors were not analyzed in the model. Although different provisional crown failure rates were calculated for the Comprehensive Care Clinic ( 25 percent) versus the Fixed Prosthodontic Clinic (17 percent), this risk factor was not statistically significant in the logistic model. Although students are encouraged to remain in the same clinic for the duration of treatment, in some instances, treatment was initiated in the Comprehensive Care Clinic and was completed in the Fixed Prosthodontic Clinic, thus possibly affecting results for this risk factor.

The pilot study was the first quality assurance initiative undertaken to track one aspect of care provided for patients seen in the Urgent Care Clinic at the UNC School of Dentistry. This study successfully demonstrated the feasibility of using the EPR master 
database to query useful data for auditing internal quality of care. With this framework in place, the general model may be applied to any clinical setting or procedural concern in which continuity of care is vital to executing successful treatment plans. For example, provisional failure rates by faculty can be monitored on an ongoing basis, and specific departmental feedback can be given to individual faculty to encourage improved oversight of predoctoral dental procedures. Alternatively, this entire conceptual framework could be applied to other clinics, which might benefit from tracking failure rates of direct restorations, implant crowns, removable prostheses, and so forth by type or location in the dental arches and what occurred prior to and following the occurrence. All of these quality of care concerns are facilitated through querying EPR, making progress notes, and subsequently analyzing the data using spreadsheet programs such as Microsoft Excel or Access. We endorse the potential benefit of using a database software system to establish an ongoing method of assessing continuity of clinical care and generate comparative reports from a constantly updated relational database.

Comparative studies including several dental institutions would permit assessment of provisional restoration success rates between schools and identification of possible educational and clinical deficiencies. We would encourage collaborative efforts among prosthodontic departments, dental school administrative units, and industry leaders to reevaluate provisional crown usage in clinical practice and develop ways to reduce retreatments. Similar data for provisionals placed in private practice would provide additional perspective on school performance.

\section{Acknowledgments}

We would like to thank Dr. Jim George, Dr. Karen Tiwana, and Dr. Jess Arbon for their assistance on this project.

\section{REFERENCES}

1. Rosenstiel SF. Contemporary fixed prosthodontics. 2nd ed. St. Louis: Mosby, 2001:380-416.

2. Christensen GJ. Tooth preparation and pulp degeneration. J Am Dent Assoc 1997;128(3):353-4.

3. Seltzer S, Bender IB. The dental pulp: biologic considerations in dental procedures. $3^{\text {rd }}$ ed. Philadelphia: J.B. Lippincott, 1984:191.

4. Larato DC. The effect of crown margin extension on gingival inflammation. J South Calif Dent Assoc 1969;37:476.
5. Burke FJ, Murray MC, Shortall AC. Trends in indirect dentistry: provisional restorations, more than just a temporary. Dent Update 2005;32(8):443-52.

6. Youdelis RA, Faucher R. Provisional restorations: an integrated approach to periodontics and restorative dentistry. Dent Clin North Am 1980;24:285-303.

7. Zinner ID, Trachtenberg DI, Miller RD. Provisional restorations in fixed partial prosthodontics. Dent Clin North Am 1989;33:355-77.

8. Hyde JD, Arbon JD, Bader JD, Kanoy BE, Shugars DA. Patterns of retreatment in a dental school urgent care clinic. J Dent Res 2006;85(Special Issue A).

9. Oginni AO. Failures related to crowns and fixed partial dentures fabricated in a Nigerian dental school. J Contemp Dent Pract 2005;6(4):136-43.

10. Yilmaz A, Baydas S. Fracture resistance of various temporary crown materials. J Contemp Dent Pract 2007;8(1): 44-51.

11. Gegauff AG, Pryor HG. Fracture toughness of provisional resins for fixed prosthodontics. J Prosthet Dent 1987;58:23-9.

12. Osman YI, Owen CP. Flexural strength of provisional restorative materials. J Prosthet Dent 1993;70:94-6.

13. Diaz-Arnold AM, Dunne JT, Jones AH. Microhardness of provisional fixed prosthodontic materials. J Prosthet Dent 1999;82:525-8.

14. Kanakuri K, Kawamoto Y, Kakehashi Y, Matsumura H. Influence of temporary cements on bond strength between resin-based luting agents and dentin. Am J Dent 2006;19(2):101-5.

15. Kelsey WP, Latta MA, Blankenau RJ. Effect of provisional restorations on dentin bond strengths of resin cements. Am J Dent 1998;11(1):67.

16. Bayindir F, Akyil MS, Bayindir YZ. Effect of eugenol and non-eugenol containing temporary cement on permanent cement retention and microhardness of cured composite resin. Dent Mater J 2003;22(4):592-9.

17. Taskonak B, Sertgoz A. Two-year clinical evaluation of lithia-disilicate-based all-ceramic crowns and fixed partial dentures. Dent Mater J 2006;22(11):1008-13.

18. Bischof M, Nedir R, Abi Najm S, Szmukler-Moncler S, Samson J. A five-year life-table analysis on wide neck ITI implants with prosthetic evaluation and radiographic analysis: results from a private practice. Clin Oral Implants Res 2006;17(5):512-20.

19. Wegner PK, Freitag S, Kern M. Survival rate of endodontically treated teeth with posts after prosthetic restoration. J Endod 2006;32(10):928-31.

20. De Backer H, Van Maele G, De Moor N, Van den Berghe L, De Boever J. A 20-year retrospective survival study of fixed partial dentures. Int J Prosthod 2006;19(2):143-53.

21. Block M, Finger I, Castellon P, Lirettle D. Single tooth immediate provisional restoration of dental implants: technique and early results. J Oral Maxillofac Surg 2004;62(9):1131-8.

22. Drago CJ, Lazzara RJ. Immediate provisional restoration of Osseotite implants: a clinical report of 18-month results. Int J Oral Maxillofac Implants 2004;19(4):534-41.

23. American Dental Association. Accreditation standards for dental education programs. Chicago: Commission on Dental Accreditation, American Dental Association, 2007. 